\title{
Development of a Kinetic Model of Boehmite Dissolution in Caustic Solutions Applied to Optimize Hanford Waste Processing
}

\author{
R. S. Disselkamp \\ Washington River Protection Solutions, LLC \\ Richland, WA 99352 \\ U.S. Department of Energy Contract DE-AC27-08RV14800

$\begin{array}{lll}\text { EDT/ECN: } & \text { DRF } & \text { UC: N/A } \\ \text { Cost Center: } & \text { 2GB00 } & \text { Charge Code: } \\ \text { B\&R Code: } & \text { N/A } & \text { Total Pages: } 28\end{array}$

Key Words: Kinetic model, boehmite, gibbsite, aluminate, caustic dissolution, saturation concentration, Hanford waste.

Abstract: The leaching of aluminum solids from Hanford waste is a key step in reducing the amount of High Level Waste (HLW) during operation of the Waste Treatment Plant (WTP). This report presents an empirical kinetic model that can be used to estimate the leaching of boehmite in Hanford waste as a function of the following parameters: 1) hydroxide concentration; 2) temperature; 3) specific surface area of boehmite; 4) initial soluble aluminate plus gibbsite present in waste; 5) concentration of boehmite in the waste; and 6) (pre-fitted) Arrhenius kinetic parameters.

TRADEMARK DISCLAIMER. Reference herein to any specific commercial product, process, or service by trade name, trademark, manufacturer, or otherwise, does not necessarily constitute or imply its endorsement, recommendation, or favoring by the United States Government or any agency thereof or its contractors or subcontractors.
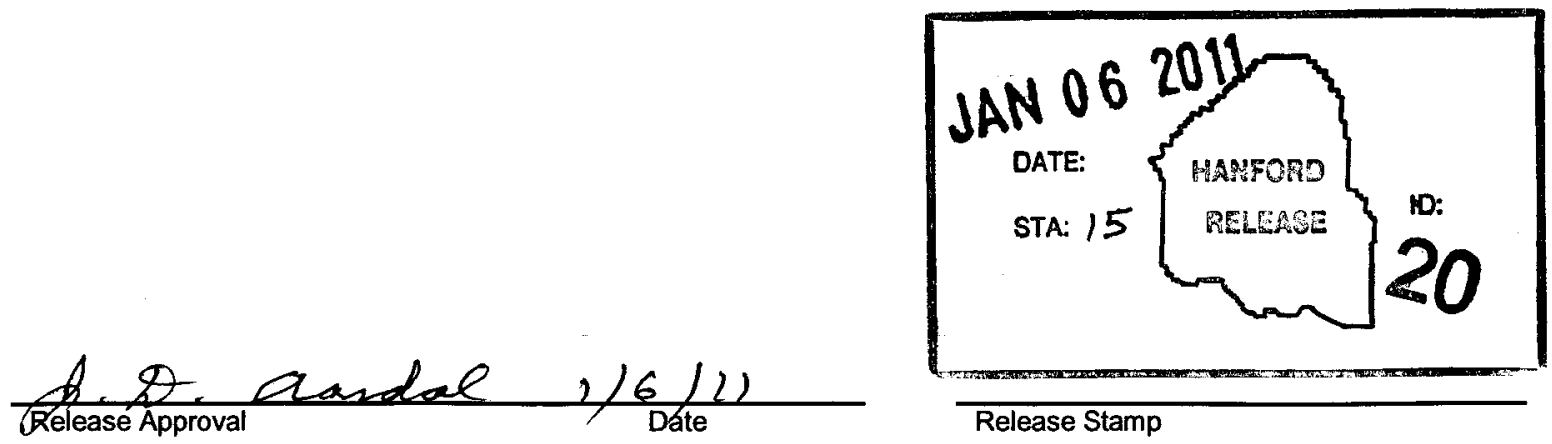

\section{Approved For Public Release}




\section{Development of a Kinetic Model of Boehmite Dissolution in Caustic Solutions Applied to Optimize Hanford Waste Processing}

\section{R.S. Disselkamp}

Washington River Protection Systems, LLC

Date Published

January 2011

Prepared for the U.S. Department of Energy

Assistant Secretary for Environmental Management

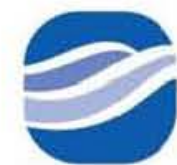

washington river protectionsolutions

P.O. Box 850

Richland, Washington

Contractor for the U.S. Department of Energy

Office of River Protection under Contract DE-AC27-08RV14800 


\section{EXECUTIVE SUMMARY}

Boehmite (e.g., aluminum oxyhydroxide) is a major non-radioactive component in Hanford and Savannah River nuclear tank waste sludge. Boehmite dissolution from sludge using caustic at elevated temperatures is being planned at Hanford to minimize the mass of material disposed of as high-level waste (HLW) during operation of the Waste Treatment Plant (WTP). To more thoroughly understand the chemistry of this dissolution process, we have developed an empirical kinetic model for aluminate production due to boehmite dissolution.

Application of this model to Hanford tank wastes would allow predictability and optimization of the caustic leaching of aluminum solids, potentially yielding significant improvements to overall processing time, disposal cost, and schedule. This report presents an empirical kinetic model that can be used to estimate the aluminate production from the leaching of boehmite in Hanford waste as a function of the following parameters: 1) hydroxide concentration; 2) temperature; 3) specific surface area of boehmite; 4) initial soluble aluminate plus gibbsite present in waste; 5) concentration of boehmite in the waste; and 6) (pre-fit) Arrhenius kinetic parameters. The model was fit to laboratory, non-radioactive (e.g. "simulant boehmite") leaching results, providing bestfit values of the Arrhenius A-factor, $\mathbf{A}$, and apparent activation energy, $\mathrm{E}_{\mathrm{A}}$, of $\mathbf{A}=5.0 \times 10^{12}$ hour $^{-1}$ and $\mathrm{E}_{\mathrm{A}}=90 \mathrm{~kJ} / \mathrm{mole}$. These parameters were then used to predict boehmite leaching behavior observed in previously reported actual waste leaching studies. Acceptable aluminate versus leaching time profiles were predicted for waste leaching data from both Hanford and Savannah River site studies. 


\section{TABLE OF CONTENTS}

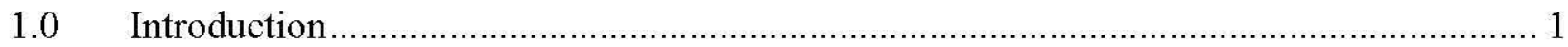

2.0 Boehmite Dissolution Kinetic Model Development.............................................. 4

$2.1 \quad$ Experimental Datasets ............................................................................... 9

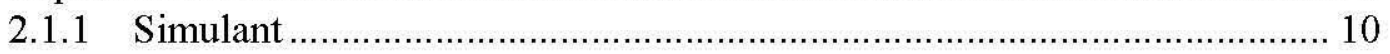

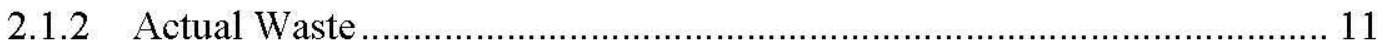

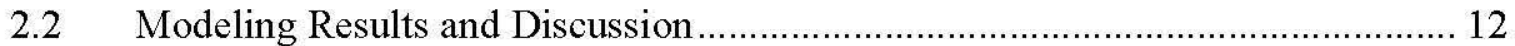

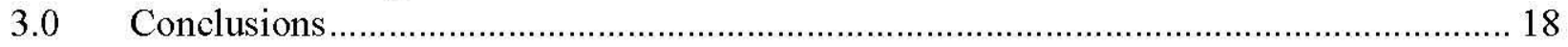

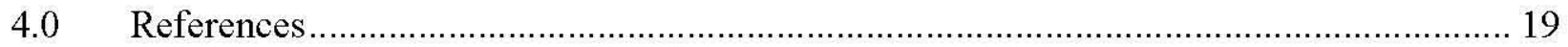

\section{TABLE OF FIGURES}

Figure 2-1. Aluminate concentration versus time for eight simulant datasets taken from PNNL18176. Four contain significant initial aluminate. Experimental conditions are provided in Table 2-2. Experimental data are symbols; fit model results are curves.

Figure 2-2. Aluminate concentration versus time for five actual waste experiments in PNNL12026. Experimental conditions are provided in Table 2-3. Experimental data are symbols; model predictions are curves.

Figure 2-3. Aluminate concentration versus time for four REDOX waste experiments described in PNNL-17368. Experimental conditions are provided in Table 2-3. Experimental data are symbols; model predictions are curves.

Figure 2-4. Aluminate concentration versus time for the SRNL waste experiment detailed in SRNL-STI-2009-00180. Experimental data are symbols; model results are curves. $A=5.0 \times 10^{12}$, $\mathrm{E}_{\mathrm{A}}=90 \mathrm{~kJ} / \mathrm{mole}$ for SRNL-T12(M).

\section{TABLE OF TABLES}

Table 2-1. Description and Units used for Parameters in Eq. (13). (2 pages) .......................... 6

Table 2-2. Initial Conditions of the Simulant Boehmite Dissolution Datasets.......................... 10

Table 2-3. Initial Conditions of the Actual Waste Sample Datasets. 


\section{LIST OF TERMS}

\section{Abbreviations and Acronyms}

A

A

$\mathrm{Al}$

$\mathrm{Al}(\mathrm{OH})_{3}$ $\mathrm{AlOOH}$

Atm

(aq)

DOE

$\mathrm{E}_{\mathrm{A}}$

Eq.

HLW

LAW

$\mathrm{NaAl}(\mathrm{OH})_{4}$

$\mathrm{R}$

REDOX

RMSE

(s)

SEM

SRNL

$\mathrm{T}$

$\mathrm{t}$

TEM

\section{Units}

${ }^{\circ} \mathrm{C}$

$\mathrm{g}$

$\mathrm{J}$

K

$\mathrm{kJ}$

$\mathrm{L}$

$\mathrm{M}$

$\mathrm{mL}$

$\mu \mathrm{m}$

$\mathrm{m}$

$\mathrm{M}$

$\mathrm{nm}$

$\mathrm{wt} \%$
Arrhenius A-factor

aluminate

aluminum

gibbsite

boehmite

atmospheres

aqueous

Department of Energy

Apparent activation energy

Equation

High-level waste

Low-activity waste

sodium aluminate

gas constant

Reduction- Oxidation

Root mean square error

solid

scanning electron microscopy

Savannah River National Laboratory

temperature

time

transmission electron microscopy

degrees Celsius

grams

Joule

kelvin

kilojoules

Liter

meter

milliliter

micrometer

molal (mole/kg)

molar (mole/L)

nanometer

weight percent 


\subsection{INTRODUCTION}

One of the primary missions of Hanford Tank Farm operations is to manage approximately 56 million gallons of wastes, most of which originated during the reprocessing of spent nuclear fuel to produce plutonium. The Department of Energy (DOE) intends to separate this waste and dispose of it as either vitrified high-level radioactive waste (HLW), or as a low-activity waste (LAW) fraction that will be pretreated and immobilized prior to on-site disposal at Hanford.

Of particular interest is minimizing HLW through dissolution of aluminum from the sludge material during pretreatment. This aqueous dissolved aluminum will subsequently be disposed of as LAW. There are three chemicals in Hanford waste that account for a majority of the aluminum, as described in "Determining Aluminum Compounds and Amounts in Hanford Tank Waste" (Gimpel and Reynolds 2008):

1) boehmite $(\mathrm{AlOOH})$;

2) gibbsite $\left[\mathrm{Al}(\mathrm{OH})_{3}\right]$; and

3) soluble sodium aluminate $\left[\mathrm{NaAl}(\mathrm{OH})_{4}\right]$.

It has been shown that boehmite is more stable than gibbsite, as indicated in "Dissolution/Precipitation Kinetics of Boehmite and Gibbsite: Application of a pH-Relaxation Technique to Study Near-Equilibrium Rates" (Bénézeth et al. 2008), LBL-21482, Thermochemical Properties of Gibbsite, Bayerite, Boehmite, Diaspore, and the Aluminate Ion between 0 and $350^{\circ} \mathrm{C}$, "Comprehensive Model of Synthetic Bayer Liquors. Part 3. Sodium Aluminate Solutions and the Solubility of Gibbsite and Boehmite" (Konigsberger et al. 2006), and "Kinetics of Boehmite Precipitation from Supersaturated Sodium Aluminate Solutions" (Skoufadis et al. 2003). As a result, boehmite has a lower tendency to dissolve and requires longer leaching durations (e.g. hours to days), even at elevated temperatures.

Gibbsite dissolution to aluminate occurs readily at moderate temperature, provided there is sufficient hydroxide available. The aluminum solids data used for our analysis were leached at elevated temperatures $\left(\mathrm{T}>60^{\circ} \mathrm{C}\right)$ and free hydroxide concentrations between 1 and 8 molal $(\mathrm{m})$. Under these conditions, we can assume that gibbsite is completely dissolved after the first time interval of leaching (typically 1 hour) due to its rapid dissolution kinetics at high temperatures and sodium hydroxide concentrations ["The Dissolution and Interactions of Gibbsite Particles in Alkaline Media" (Addai-Mensah et al. 2000)].

The chemical reactions for hydroxide-induced dissolution of solid (s) boehmite and gibbsite are provided by equations (1) and (2), respectively.

$$
\begin{gathered}
\text { boehmite } \leftrightarrow \text { aluminate : } \mathrm{AlOOH}(s)+\mathrm{H}_{2} \mathrm{O}+\mathrm{OH}^{-} \stackrel{k_{1}}{\longleftarrow} \mathrm{s} \\
\text { where } K_{1}=\frac{k_{1}}{k_{-1}} \text { (Equilibrium expression) }
\end{gathered}
$$




$$
\begin{gathered}
\text { gibbsite } \leftrightarrow \text { aluminate }: A l(O H)_{3}(s)+O H^{-} \stackrel{k_{2}}{\longleftarrow} A l(O H)_{4}{ }^{-} \text {(aq) (fast) } \\
\text { where } K_{2}=\frac{k_{2}}{k_{-2}} \text { (Equilibrium expression) }
\end{gathered}
$$

These reactions indicate that both boehmite and gibbsite dissolve to yield aqueous (aq) aluminate $\left[\mathrm{Al}(\mathrm{OH})_{4}^{-}\right]$. The equations above are written as reversible reactions, where the reverse reactions proceed directly from aluminate. Although boehmite formation directly from aluminate is not a requirement of the model development and its applicability presented here, it simplifies the kinetic analysis of its formation by not requiring production through the gibbsite intermediate. Inclusion of the latter would only add complexity to the model through the addition of another chemical reaction while not changing the models predictive capabilities.

The equilibrium constants of equations (1) and (2) are such that $\mathrm{K}_{1}<\mathrm{K}_{2}$ at all temperatures of interest in this study (i.e., aluminate concentration with respect to boehmite saturation is less than that of gibbsite saturation). Therefore, an accurate approximation for boehmite dissolution kinetics would be to assume all gibbsite dissolves rapidly at $\mathrm{t}=0$, leaving only the reversible kinetics of Eq. (1) for our model. In practice, all gibbsite will dissolve under similar conditions, leaving aluminate concentration limited by boehmite solubility. Accordingly, a key simplification is to group all of the aluminum in the system into two categories: (1) boehmite; and (2) gibbsite plus aluminate. A single reversible reaction can then be developed, treating boehmite dissolution as a process ultimately proceeding to aluminate saturation with respect to boehmite.

The impact of gibbsite dissolution on boehmite kinetics is important due to the inhibitory effect arising from its aluminate reaction product. This is incorporated in our model, as all gibbsite is assumed dissolved at the initial time step and is included in the initial aluminate inventory. The aluminate produced due to boehmite leaching will consequently achieve saturation sooner due to this increase in initial aluminate in solution and the low saturation limits for aluminate that can be produced due to boehmite dissolution.

The distinction between boehmite, gibbsite, and aluminate will become important in the model development considered in this study, and is a key to boehmite dissolution at both high and low total aluminate concentrations. Incidentally, although the developed model will be generally applicable under all aluminate concentration regimes, all of the datasets considered in this paper were sub-saturated with respect to gibbsite. Only one dataset achieved saturation with respect to boehmite.

Substantial information exists in both government reports and journal literature detailing dissolution/solubility studies of boehmite in caustic solutions. One of the first studies was performed in "Studies on Recrystallised Aluminum Mono-Hydroxide Precipitates. Kinetics of Dissolution by Sodium Hydroxide Solutions" (Packter 1976) at low solids (e.g. 1 wt\%) concentrations and less than 1 molar hydroxide concentration. Their solutions contained a relatively small amount of aluminate relative to the boehmite saturation limit. The (consumed) hydroxide concentration was controlled during leaching, with a model presented to interpret their results. We cannot apply their model to Hanford waste leaching since proposed aluminum leaching in Hanford wastes will possess, in certain instances, aluminate concentrations near the 
saturation limit with respect to boehmite. The saturation concentration of aluminate with respect to boehmite is important, as dissolution of boehmite will occur with a rate greater for systems further removed from equilibrium. A kinetic model must account for this affect.

Motivating this study was the need for a boehmite dissolution kinetic model applicable to specific radioactive waste slurries, including those near boehmite saturation. Prior work detailed in Skoufadis et al. 2003, "Gibbsite to Boehmite Transformation in Strongly Caustic and Nitrate Environments" (Gong et al. 2003), and Konigsberger et al. 2006 have investigated the kinetics of boehmite precipitation from aluminate, while "Effect of Temperature and Alumina/Caustic Ratio on Precipitation of Boehmite in Synthetic Sodium Aluminate Liquor" (Dash et al. 2007) investigated the kinetics of boehmite precipitation from gibbsite. Aluminum solids dissolution and speciation from radioactive sludge materials was analyzed in "Effects of Sodium Hydroxide and a Chelating Agent on the Removal of Aluminum from Radioactive Sludge" (Spencer et al. 2005), "Modeling of Boehmite Leaching from Actual Hanford High-Level Waste Samples" (Peterson et al. 2007), "Boehmite Actual Waste Dissolution Studies" (Snow et al. 2008), and "Raman Study of Aluminum Speciation in Simulated Alkaline Nuclear Waste" (Johnston et al. 2002). The ultimate intention of these studies was the development of a generic model that could be readily adapted for application to specific nuclear waste streams. An empirical model was proposed in Peterson et al. 2007, which was applied to caustic leaching of boehmite from Hanford wastes. Their model was an engineering correlation fit to several datasets. The disadvantage of their approach was that a correlation could not readily be extrapolated to experimental conditions not specifically parameterized.

This paper details the construction of an alternative kinetic model where parameters of interest (e.g., free hydroxide concentration, temperature, boehmite/gibbsite/aluminate concentrations, boehmite specific surface area, etc.) are incorporated. The derived kinetic rate law expression explicitly treats the conditions for which our leaching predictions are needed. The model has at its origin a dissolution/re-precipitation rate law expression that may provide enhanced accuracy for input outside its parameterization scope. To validate this model we used information from available laboratory data to reproduce their observed results. This model can provide application to various wastes, as well as provide process optimization through caustic and temperature adjustment. The objective of this work is to produce a model that will be used to develop caustic leaching flowsheets. This will provide a significant improvement in the prediction of waste treatment performance at the Hanford site.

Initial dissolved aluminum in solution for this model consists of sodium aluminate plus all dissolvable gibbsite. Kinetic parameters for aluminate production due to boehmite dissolution were determined through the development and application of a rate law expression. This model's kinetic parameters were fit using data from studies conducted under a broad range of parameters, including hydroxide concentrations, temperature, and initial gibbsite/boehmite concentrations. The rate law expression was deemed acceptable since the dissolution behavior was modeled with an acceptable accuracy (less than $20 \%$ error) for up to 24 hours.

In this report, we begin by presenting the model development. Second, the model parameters are determined through fits to waste simulant studies. Finally, the model, incorporating these fit parameters, is assessed using actual waste leach data to predict time-to-aluminate concentration 
profiles. This report is a detailed description of calculations performed, as presented in a spreadsheet issued by the author in December 2010 [SVF-1866 Rev.1, Development of a Kinetic Model of Boehmite Dissolution in Caustic Solutions Applied to Optimize Hanford Waste Processing].

\subsection{BOEHMITE DISSOLUTION KINETIC MODEL DEVELOPMENT}

The model developed in this study contains both a forward (dissolution) and reverse (precipitation) reaction. As previously discussed, to simplify the kinetic modeling of aluminate production due to boehmite dissolution, it is convenient to approximate the initial aluminate concentration as including aluminate that would arise from $100 \%$ gibbsite dissolution plus any initial dissolved (sodium) aluminate in solution. With this assumption, one then has initial ( $\mathrm{t}=0$ hour) total aqueous aluminate, from aluminate plus gibbsite, and total boehmite solids for the leaching slurry solution.

Our boehmite dissolution rate model is derived from a simplified general chemical reaction of dissolution and precipitation processes presented in Chapter 1 of Kinetics of Water-Rock Interaction (Brantley et al. 2008), that in turn was interpreted from an earlier text, Chemical Kinetics (Laidler, 1987). Our approach is two-fold. We begin by deriving a general integrated rate law that is rigorously accurate for a general

$B$ (Boehmite) $\underset{k_{-1}}{\stackrel{k_{1}}{\longleftrightarrow}} A$ (Gibbsite, Aluminate) reversible reaction, and identify terms in the expression applicable to our aluminum leaching system. We then extend this integrated rate law expression to describe additional features of our particular two-phase system consisting of boehmite-containing solids in an aqueous slurry.

In the approach taken by Brantley et al. 2008 and Laidler 1987, they presented an integrated functional form of a generic dissolution kinetic model:

$$
\begin{gathered}
B \underset{k_{-1}}{\stackrel{k_{1}}{\rightleftarrows}} A \\
\frac{d x}{d t}=k_{1}\left(A_{B}-x\right)-k_{-1}\left(x+A_{G A}\right)
\end{gathered}
$$

For our use (with caustic in excess) Eq. (1) simplifies to Eq. (3), where the reversible boehmite $(B)$ to aluminate $(A)$ dissolution process is the only reaction considered. The net rate of aluminate formed due to boehmite dissolution, $\frac{d x}{d t}$, is quantified by the dissolution rate minus the precipitation rate as presented in Eq. (4). At the onset of dissolution (e.g. $t=0$ ) the initial aluminate concentration due to boehmite dissolution is $A_{B}$ and the initial aluminate concentration in solution (e.g. gibbsite plus aluminate, referred to as gibbsite-aluminate or noted as $G A$ ) is given as $A_{G A}$. The concentration unit adopted in this study is molal. The rate expression of Eq. (4) can be re-arranged to a constant term plus a term linear in the amount of aluminate produced from boehmite dissolution $(x)$ : 


$$
\frac{d x}{d t}=\left[k_{1} A_{B}-k_{-1} A_{G A}\right]-\left[\left(k_{1}+k_{-1}\right) x\right]
$$

This model is applied in situations where the $A_{G A}$ concentration is less than the aluminate saturation concentration with respect to boehmite. We have not explored its use in the other situation, where the $\mathrm{A}_{\mathrm{GA}}$ concentration is more that the aluminate concentration with respect to boehmite saturation. This does not restrict its application here or for any system modeling aluminate production due to the boehmite dissolution processes of interest at Hanford. At sufficiently long dissolution time, the amount of aluminate in solution will be equal to the equilibrium aluminate due to dissolved boehmite, $A_{B, e}$. For this condition, the term $d x / d t=0$ resulting in the following expression:

$$
0=\left[k_{1} A_{B}-k_{-1} A_{G A}\right]-\left[\left(k_{1}+k_{-1}\right) A_{B, e}\right]
$$

The term $A_{B, e}$ is equivalent to the aluminate saturation concentration due to boehmite dissolution at equilibrium arising from first-order kinetics, where 1 molal of $B$ dissolves to produce 1 molal $A$ in Eq. (3). This expression can be solved for $A_{G A}$ yielding:

$$
A_{G A}=\frac{k_{1} A_{B}-\left(k_{1}+k_{-1}\right) A_{B, e}}{k_{-1}}
$$

This resultant equality for $A_{G A}$ is then substituted into Eq. (5) to obtain:

$$
\frac{d x}{d t}=\left(k_{1}+k_{-1}\right)\left(A_{B, e}-x\right)
$$

The final manipulation, used for substitution, is to again use Eq. (6), this time solving for $k_{-1}$.

$$
k_{-1}=k_{1}\left[\frac{A_{B}-A_{B, e}}{A_{G A}+A_{B, e}}\right]
$$

Equation (9) is then substituted into Eq. (8) yielding our desired rate law expression:

$$
\frac{d x}{d t}=k_{1}\left(\frac{A_{B}+A_{G A}}{A_{B, e}+A_{G A}}\right)\left(A_{B, e}-x\right)
$$

The rate law expression of Eq. (10) can now be rearranged, integrated, and subjected to boundary conditions. The boundary conditions are such that, at time zero there is no aluminate in solution due to boehmite dissolution while at time the amount of aluminate in solution due to boehmite dissolution is equal to the total aluminate at time $t$ minus any aluminate initially in solution (e.g. $x=0$ at $t=0$ and $x=A(t)-A_{G A}$ at $\left.t=t\right)$. The integrated boundary value expression is given in Eq. (11) below.

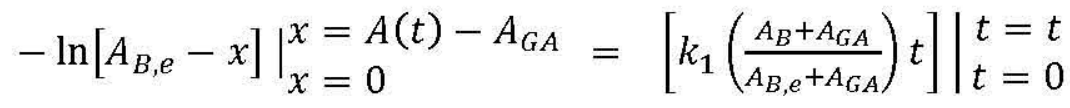

Solving, based upon these limits of integration, leads to the expression: 


$$
A(t)=A_{G A}+\left(A_{B, e}\right)\left[1-\exp \left(-\left(\frac{A_{B}+A_{G A}}{A_{B, e}+A_{G A}}\right) k_{1} t\right)\right]
$$

The ratio term, $\frac{A_{B}+A_{G A}}{A_{B, e}+A_{G A}}$, compares the total potential aluminate concentration in the numerator to the maximum aluminate concentration at equilibrium in the denominator. Hence, this ratio will be greater than or equal to one, with the limit such that the greater the ratio is, the closer to equilibrium the system attains at any given time. This is reasonable because, for example, as the solid boehmite concentration in the slurry increases, the system will approach equilibrium (e.g. saturation) more rapidly.

Equation (12) must be expanded to achieve generality in its functional form. This expanded form can then be used to approximate the leaching behavior for all Hanford tank waste processes. Our final equation is obtained through the application of linear scaling relationships and enabling variability for changes in temperature, free hydroxide concentration (as it affects saturation concentrations), aluminum solids concentration, and specific surface area.

It is important to note in our model that only the exponential term addresses the time-dependent behavior of dissolution. The key to using Eq. (12) is to note the relevant terms contained within the rate coefficient, $k_{l}$, which depends on system parameters in the heterogeneous reacting system. Therefore, as shown in Chemical Dissolution of Metal Oxides (Blesa et al. 1994), we have set $k_{l}$ to be dependent upon the fraction of anionic charged surface sites on the mineral surface $\left(C\right.$; a requirement for dissolution), the concentration $\left(F_{B} F_{S}\right)$ and specific surface area $\left(S_{o}\right)$ of solids undergoing dissolution, the Arrhenius kinetic parameters $\left(\mathbf{A}\right.$ and $\left.\mathrm{E}_{\mathrm{A}}\right)$, and temperature (T) as shown in Eq. (13).

$$
k_{1}=C F_{B} F_{S} S_{o} \mathbf{A} \exp \left(\frac{-E_{A}}{R T}\right)
$$

A definition of these parameters, including the dimensions of these quantities, is given in Table 2-1. All of the terms in Eq. (13) are measurable values except the kinetic parameters $\mathbf{A}$ and $\mathrm{E}_{\mathrm{A}}$.

Table 2-1. Description and Units used for Parameters in Eq. (13). (2 pages)

\begin{tabular}{|l|l|l|}
\hline Parameter & Units & Description \\
\hline$A(t)$ & Molal $(m)$ & $\begin{array}{l}\text { Dissolved aluminate concentration as a function of time. Dependent } \\
\text { variable. }\end{array}$ \\
\hline$t$ & Time (hours) & Independent variable. \\
\hline$A_{G A}$ & $m$ & $\begin{array}{l}\text { Initial }(\mathrm{t}=0) \text { gibbsite plus aluminate in system. This term describes the } \\
\text { existing aluminate, plus fast dissolving aluminum-containing phases in the } \\
\text { system. Other aluminum-containing phases, such as Dawsonite, should also } \\
\text { be included in this term. }\end{array}$ \\
\hline$A_{B, e}$ & $m$ & $\begin{array}{l}\text { The total aluminate produced due to boehmite saturation. Depends } \\
\text { principally on hydroxide concentration and temperature. }\end{array}$ \\
\hline$C$ & $m$ & $\begin{array}{l}\text { This term is the obtained by converting the initial (t=0) concentration of } \\
\text { boehmite in the slurry into an equivalent amount of dissolved aluminate. }\end{array}$ \\
\hline & dimensionless & $\begin{array}{l}\text { The pH-dependent fraction of charged sites. At highly alkaline conditions, } \\
\text { where [OH'] }>1 \mathrm{M} \text {, we assume all C values take the value of one. This } \\
\text { assumption can be revisited if more surface charge data at high pH becomes } \\
\text { available. }\end{array}$ \\
\hline
\end{tabular}


Table 2-1. Description and Units used for Parameters in Eq. (13). (2 pages)

\begin{tabular}{|c|c|c|}
\hline Parameter & Units & Description \\
\hline$F_{B}$ & g(solids) $/ g$ (slurry) & $\begin{array}{l}\text { The fractional amount of total insoluble solids per total slurry mass. This } \\
\text { quantity is equal to g(solids)/g(slurry) prior to leaching. }\end{array}$ \\
\hline$F_{S}$ & $\begin{array}{l}\mathrm{g} \text { (Al-as- } \\
\text { boehmite) / } \mathrm{g} \\
\text { (solids) }\end{array}$ & $\begin{array}{l}\text { The fractional amount of boehmite in the solids to be leached, where } \\
\text { gibbsite is not included in the estimation of the solids fraction. This } \\
\text { quantity is equal to } \mathrm{g}(\mathrm{Al} \text {-as-boehmite) } \mathrm{g} \text { (solids) prior to leaching. For the } \\
\text { simulant experiments } \mathrm{F}_{\mathrm{S}}=1 \text {. However, for actual waste studies, } \mathrm{F}_{\mathrm{S}}<1 \text {, as } \\
\text { other solids exist in the leaching solutions (see Table 2-3). }\end{array}$ \\
\hline$S_{0}$ & dimensionless & $\begin{array}{l}\mathrm{S}_{\mathrm{o}}=\mathrm{S} / 1 \frac{\mathrm{m}^{2}}{\mathrm{~g}} \text {, where } \mathrm{S} \text { is } \frac{\mathrm{m}^{2}}{\mathrm{~g}} \text { specific surface area of boehmite solids. The } \\
\text { actual waste value of } \mathrm{S} \text { in } \frac{\mathrm{m}^{2}}{\mathrm{~g}} \text { can be estimated from its average particle size, } \\
\text { approximated using a spherical particle shape and boehmite density. It is } \\
\text { preferable to have } \mathrm{S}_{\mathrm{o}} \text { defined, appropriate for leaching, as waste-specific } \\
\text { information. Division by } 1 \mathrm{~m} / \mathrm{g} \text { makes this term dimensionless, yielding } \\
\text { Arrhenius A-factor with conventional units of } 1 / \text { time. }\end{array}$ \\
\hline $\mathbf{A}$ & 1/hours & Arrhenius A-factor for rate coefficient describing dissolution. \\
\hline$E_{A}$ & $\mathrm{~J} / \mathrm{mole}$ & Arrhenius apparent activation energy. \\
\hline$R$ & $\mathrm{~J} / \mathrm{K}-\mathrm{mol}$ & Ideal gas law constant, $\mathrm{R}=8.314 \mathrm{~J} / \mathrm{K}-\mathrm{mol}$. \\
\hline$T$ & Kelvin & Absolute temperature of leaching solution. \\
\hline
\end{tabular}

To capture the chemistry of the interfacial heterogeneous dissolution processes, the terms $F_{S}$ and $F_{B}$ are included in Eq. (13) to account for the mass of boehmite in the slurry solution. Here, $F_{S}$ is the fraction of aluminum in the solids prior to leaching (g-Al/g-solids) and $F_{B}$ is the solids concentration (g-solids/g-slurry). The specific surface area of boehmite in actual waste samples, $S$, is also included to account for the available surface area for leaching per mass of boehmite. The parameter $S_{o}$ is defined as the specific surface area of boehmite divided by $1 \mathrm{~m}^{2} / \mathrm{g}$ to make the term dimensionless. The units of $\mathrm{g} / \mathrm{m}^{2}$ could just have easily been incorporated into the Arrhenius A-factor's units without changing the model's applicability. As a result, in this paper we can use the $S$ and $S_{o}$ terms interchangeably. These terms are necessary to account for the heterogeneous nature of the dissolution/precipitation processes. A final term, $C$, is the ratio of anionic charge on the surface of boehmite to that at $\mathrm{pH}=12$, which is necessary for desorption/dissolution of boehmite into the aqueous phase. This is explained further below. These terms comprise the available surface area portion of the overall forward dissolution $\left(k_{l}\right)$ rate coefficient, $C F_{S} F_{B} S_{o}$.

The remaining parameter that requires further description is the fraction of charged surface sites, $C$. The inclusion of this term arises from the molecular dissociation of protons from the surface, forming the surface ion $\mathrm{AlOO}^{-}$. This is a key species that dissociates from the surface and is a factor controlling the kinetics of dissolution, as shown in Brantley et al. 2008, Blesa et al. 1994, "Effect of Solubility on the Determination of the Protonable Surface Site Density of Oxyhydroxides" (Lefèvre et al. 2004), and "The Coordination Chemistry of Weathering: I. Dissolution Kinetics of $\delta-\mathrm{Al}_{2} \mathrm{O}_{3}$ and $\mathrm{BeO}$ " (Furrer and Stumm 1986). Since a highly alkaline surface charge for boehmite could not be found, we have approximated the boehmite surface charge density to be similar to that of $\gamma$-alumina $\left(\mathrm{Al}_{2} \mathrm{O}_{3}\right)$. This assumption is reasonable due to the following two observations being true for our system:

(1) Boehmite and $\gamma-\mathrm{Al}_{2} \mathrm{O}_{3}$ surfaces possess similar aluminum coordination surface structures as described in "Solid-State ${ }^{1} \mathrm{H}$ NMR Studies of Aluminum Oxide Hydroxides and 
Hydroxides" (Piedra et al. 1996) and "Boehmite-Derived g-Alumina System. 2. Consideration of Hydrogen and Surface Effects" (Paglia et al. 2004), and

The anionic surface charge is saturated in our $\mathrm{pH}$ range.

The constant $C$ represents the fraction of reactive sites on the boehmite surface that are charged. Leferve et al. 2004 determined that the surface charge of $\gamma-\mathrm{Al}_{2} \mathrm{O}_{3}$ approaches saturation (e.g. $C=1$ ) when $\mathrm{pH}>12$. Therefore we assume boehmite also approaches a constant surface charge as $\mathrm{pH}$ increases, with our value being the maximum boehmite can undertake due to the high hydroxide concentration used for boehmite leaching ( 1 to 8 molal). Hence, $C$ was assigned a value of one for all experiments evaluated in this study.

At lower hydroxide concentrations, $C$ would have a different value and be reminiscent of models used at lower $\mathrm{pH}$, such as that in Bénézeth et al. 2008. This phenomenon was first discovered for the acid-assisted dissolution reactions for $\delta-\mathrm{Al}_{2} \mathrm{O}_{3}$ and $\mathrm{BeO}$ by Furrer and Stumm 1986. In their study, the inferred surface charge, rather than the bulk solution $\mathrm{pH}$, controlled the dissolution rate of these minerals. This phenomenon serves as the basis for the inclusion of $C$ within our model which, for purposes of generality, was left within our equation despite being assigned a value of unity. This also differentiates our model from the previous study by Peterson et al. 2007.

The values of $S$ (e.g. $S_{o}$ ) for the simulant studies were provided by the manufacturer and detailed in PNNL-18176, Development and Characterization of Boehmite Component Simulant. For the actual waste studies, $S$ was either calculated or provided with the experimental analysis. For the actual waste studies which did not provide values of $S$, its value was calculated assuming the particles had a spherical shape with a diameter of $100 \mathrm{~nm}$, as was done by Peterson et al. 2007, and dividing by the density of boehmite $(3.03 \mathrm{~g} / \mathrm{mL})$, yielding a value of $S=9.9 \mathrm{~m}^{2} / \mathrm{g}$. From the electron imaging studies performed by Peterson et al. 2007, a spherical shape was assumed and likely did not introduce significant error, even though the actual particles had been described as possessing a "prism" or "lozenge" shape. This was because the asymmetric axial ratio was less than 1.5:1 from their published images.

It is important to estimate the expected change during dissolution of the terms in the $C F_{S} F_{B} S_{O}$ expression. These quantities have been defined using initial values prior to dissolution, and are assumed constant throughout dissolution. As just discussed, $C$ is approximated as being unity throughout dissolution since the surface of boehmite will achieve a full "monolayer" of anionic charge under our high $\mathrm{pH}$ conditions. The remaining product, $F_{S} F_{B} S_{o}$, may vary with the degree of dissolution, serving as the basis of the shrinking core model of mineral dissolution. For boehmite, however, the recent study "Dissolution of Boehmite in Sodium Hydroxide at Ambient Pressure: Kinetics and Modeling" (Grenman et al. 2010) has shown that the product $F_{S} F_{B} S_{O}$ is proportional to $\left(D^{2} S_{o}\right)(\% B)$, where $D$ is particle diameter $(\mu \mathrm{m}), S_{o}$ is specific surface area, and $\% B$ is percent boehmite remaining after dissolution. Their analysis indicated that this product varied by less than about $4 \%$, despite $40 \%$ boehmite dissolution. For our boehmite dissolution model we assume this product is a constant and has little impact upon the total amount of boehmite dissolved. As will be seen later, this assumption does not produce significant disagreement between the model predictions of experimental leaching data. 
The terms in the exponential function of Eq. (12) are therefore manifested as a multiplicative product of the parameters. For completion, Eq. (13) is substituted into Eq. (12) to provide our master equation:

$$
A(t)=A_{G A}+\left(A_{B, e}\right)\left\{1-\exp \left[-\left(\frac{A_{B}+A_{G A}}{A_{B, e}+A_{G A}}\right) C F_{B} F_{S} S_{o} \mathbf{A} \exp \left(\frac{-E_{A}}{R T}\right) t\right]\right\}
$$

An important note about the total aluminate that can form from the initial boehmite concentration, $A_{B}$, and the amount of aluminate that can form due to boehmite dissolution at equilibrium, $A_{B, e}$. For subsaturated aluminate solutions with respect to boehmite, $A_{B}=A_{B, e}$ (e.g. all of the boehmite can dissolve). This is the case for most of the datasets considered in our analysis. However, should aluminum leaching be considered for wastes consisting of very high boehmite concentration (e.g. $A_{B}>A_{B, e}$; see Table 2-1Error! Reference source not found. for definitions), the ratio term in Eq. (14) will be greater than unity and the system will exhibit a faster approach to equilibrium aluminate concentration. The concentration of aluminate with respect to saturation for boehmite was obtained from LBL-21482.

We examine the functional form in Eq. (14) by calculating the limits of dissolved aluminate formation, $A(t)$, for $t$ approaching infinity [i.e., long time, shown in Eq. (15)], and as $t$ approaches zero [shown in Eq. (16)].

$$
\begin{aligned}
& \operatorname{limit}(A(t)) \text { as } t \rightarrow \infty ; \quad A(t \rightarrow \infty) \rightarrow A_{G A}+A_{B, e} \\
& \operatorname{limit}(A(t)) t \rightarrow 0 ; \quad A(t \rightarrow 0) \rightarrow A_{G A}
\end{aligned}
$$

We see that, as $t$ approaches a very large value, the amount of dissolved aluminate formation approaches the sum of aluminate due to the initial aluminate + gibbsite dissolved at early time plus that due to equilibrium dissolution of boehmite. As $t$ approaches zero, the amount of aluminate formed approaches the initial amount of aluminate and gibbsite dissolved at early time. These limits are to be expected and obey the behavior for our derived expression.

\subsection{EXPERIMENTAL DATASETS}

Two categories of data were used for this model. The first was from simulant caustic leaching experiments, with the second being from actual waste dissolution experiments. Simulant data were used to fit the constant Arrhenius parameters, $\mathbf{A}$ and $\mathrm{E}_{\mathrm{A}}$, for inclusion within our model. These constants were subsequently used in model validation by fitting experimental results from actual waste experiments. Descriptions of these datasets are provided below. 


\subsubsection{Simulant}

Test results for simulant boehmite caustic dissolution were taken from PNNL-18176. Their data provided a wide variety of initial conditions (i.e., free hydroxide, gibbsite, aluminate, and boehmite concentrations, specific boehmite surface area, and temperature) which we employed. In their study, commercially available boehmite (e.g. Apyral) was dissolved using an aqueous caustic $(\mathrm{NaOH})$ solution, some of which included sodium nitrate to increase ionic strength. Samples of each test solution were taken at time intervals of $1,2,4,8$, and 24 hours. A total of eight dissolution tests from their study, using Apyral AOH-20, AOH-20Y, or AOH-60 boehmite samples, were analyzed. In two of these datasets, soluble sodium aluminate was added. Parameters from these studies are shown in Table 2-2.

Table 2-2. Initial Conditions of the Simulant Boehmite Dissolution Datasets.

\begin{tabular}{|l|l|l|l|l|l|l|l|l|}
\hline Run & $\begin{array}{l}{\left[\mathrm{OH}^{-}\right]} \\
(M)\end{array}$ & $\begin{array}{l}\mathrm{FsFb}^{1}(\mathrm{~g}- \\
\text { boeh./g-slurry })\end{array}$ & $\begin{array}{l}{\left[A_{G A}\right]} \\
(m)\end{array}$ & $\begin{array}{l}{\left[A_{B}\right]} \\
(m)\end{array}$ & $\begin{array}{l}{\left[A_{B, e}\right]} \\
(m)\end{array}$ & $\begin{array}{l}\mathrm{S}_{\mathrm{o}}=\mathrm{S} /\left(1 \mathrm{~m}^{2} / \mathrm{g}\right) \\
\text { specific surface area } \\
(\text { dimensionless })\end{array}$ & $\begin{array}{l}\mathrm{T} \\
\left({ }^{\circ} \mathrm{C}\right)\end{array}$ & $\begin{array}{l}\text { Density } / \\
\% \text { water }\end{array}$ \\
\hline MTB-11 & 3.0 & 0.0177 & 0.005 & 0.061 & 0.061 & 2.4 & 79.9 & $\begin{array}{l}1.086 \\
88.96\end{array}$ \\
\hline BSM-1 & 5.8 & 0.0284 & 0.552 & 0.129 & 0.129 & 2.4 & 101.5 & $\begin{array}{l}1.188 \\
75.18\end{array}$ \\
\hline BSM-13a & 5.8 & 0.0298 & 0.018 & 0.368 & 0.368 & 2.4 & 101.0 & $\begin{array}{l}77.164 \\
77.77\end{array}$ \\
\hline BSM-15a & 4.5 & 0.0307 & 0.499 & 0.049 & 0.049 & 2.4 & 98.8 & $\begin{array}{l}7.153 \\
78.62\end{array}$ \\
\hline ATM-3 & 1.0 & 0.0098 & 0.128 & 0.053 & 0.053 & 2.4 & 100.8 & $\begin{array}{l}1.009 \\
94.32\end{array}$ \\
\hline ATM-12 & 5.0 & 0.0099 & 0.432 & 0.106 & 0.106 & 2.4 & 100.3 & $\begin{array}{l}1.251 \\
68.18\end{array}$ \\
\hline BCT2-1 & 3.0 & 0.0099 & 0.019 & 0.166 & 0.166 & 6 & 98.3 & $\begin{array}{l}1.073 \\
88.81\end{array}$ \\
\hline BCT3-5 & 7.0 & 0.0099 & 0.032 & 0.214 & 0.214 & 3 & 97.8 & $\begin{array}{l}1.199 \\
76.66\end{array}$ \\
\hline
\end{tabular}

Dissolved concentrations of aluminum were reported in molar units in PNNL-18176 and had to be converted to molal units for application within our model. This was accomplished by calculating initial solution density and percent water with the Laliberté-Cooper model, using a method described in detail in "Reconciliation of Solute Concentration Data with Water Contents and Densities of Multi-Component Electrolyte Solutions" (Reynolds and Carter 2008). As mentioned previously, concentration versus time data during dissolution was plotted and Eq. (14) was fit to the leaching data. This allowed us to determine one combination of values for the Arrhenius $\mathbf{A}$ and $\mathrm{E}_{\mathrm{A}}$ parameters to use with our model. Actual waste data were then used to evaluate the predictive capability of this model, incorporating this constant set of parameter values. 


\subsubsection{Actual Waste}

PNNL-12026, Washing and Caustic Leaching of Hanford Tank Sludge: Results of FY1998 Studies, provided results of boehmite dissolution experiments on actual waste samples from Hanford tanks B-101, BX-110, and S-101 using a variety of caustic concentrations and temperatures. In all experiments, the sludge material was first washed to remove soluble aluminate and other salts prior to leaching. These tests were analyzed at times of 5, 24, 72, and 168 hours (PNNL-12026). Initial fractional amounts of boehmite solids present (e.g. $F_{S}$ and $F_{B}$, defined in Table 2-1) for these studies are provided in Table 2-3.

Table 2-3. Initial Conditions of the Actual Waste Sample Datasets.

\begin{tabular}{|c|c|c|c|c|c|c|c|}
\hline Run & $\begin{array}{l}{\left[\mathrm{OH}^{-}\right](M)} \\
\mathrm{F}_{\mathrm{B}} \text { (g-solids/g-slurry) } \\
\mathrm{F}_{\mathrm{S}} \text { (g-boeh./g-solids) }\end{array}$ & $\begin{array}{l}{\left[A_{G A}\right]} \\
(m)\end{array}$ & $\begin{array}{l}{\left[A_{B}\right]} \\
(m)\end{array}$ & $\begin{array}{l}{\left[A_{B, e}\right]} \\
(m)\end{array}$ & $\begin{array}{l}\mathrm{S}_{\mathrm{o}}=\mathrm{S} /\left(1 \mathrm{~m}^{2} / \mathrm{g}\right) \\
\text { specific surface area } \\
\text { (dimensionless) }\end{array}$ & $\begin{array}{l}\mathrm{T} \\
\left({ }^{\circ} \mathrm{C}\right)\end{array}$ & $\begin{array}{l}\text { Density / } \\
\% \text { water }\end{array}$ \\
\hline B-101 & $\begin{array}{l}3.1 \\
0.0566 \\
0.0826\end{array}$ & 0.094 & 0.008 & 0.008 & 9.9 & 100. & $\begin{array}{l}1.075 \\
88.47\end{array}$ \\
\hline BX-110a & $\begin{array}{l}3.1 \\
0.0130 \\
0.2475\end{array}$ & 0.125 & 0.002 & 0.002 & 9.9 & 80. & $\begin{array}{l}1.090 \\
88.62\end{array}$ \\
\hline BX-110b & $\begin{array}{l}3.2 \\
0.0150 \\
0.2475\end{array}$ & 0.128 & 0.009 & 0.009 & 9.9 & 95. & $\begin{array}{l}1.082 \\
88.17\end{array}$ \\
\hline S-101a & $\begin{array}{l}1.0 \\
0.1482 \\
0.1040\end{array}$ & 0.062 & 0.128 & 0.128 & 9.9 & 95. & $\begin{array}{l}1.002 \\
96.01\end{array}$ \\
\hline S-101b & $\begin{array}{l}3.0 \\
0.2637 \\
0.1040\end{array}$ & 0.181 & 0.339 & 0.339 & 9.9 & 95. & $\begin{array}{l}1.075 \\
88.84\end{array}$ \\
\hline REDOX-1 & $\begin{array}{l}5.06 \\
0.0114 \\
0.3883\end{array}$ & 0.008 & 0.195 & 0.195 & 26 & 80. & $\begin{array}{l}1.154 \\
82.47\end{array}$ \\
\hline REDOX-2 & $\begin{array}{l}3.13 \\
0.0115 \\
0.3883\end{array}$ & 0.023 & 0.184 & 0.184 & 26 & 90. & $\begin{array}{l}1.133 \\
80.69\end{array}$ \\
\hline REDOX-3 & $\begin{array}{l}3.06 \\
0.0103 \\
0.3883\end{array}$ & 0.019 & 0.228 & 0.228 & 26 & 90. & $\begin{array}{l}1.322 \\
56.34\end{array}$ \\
\hline REDOX-4 & $\begin{array}{l}2.81 \\
0.0126 \\
0.3883\end{array}$ & 0.020 & 0.191 & 0.191 & 26 & 100. & $\begin{array}{l}1.065 \\
89.45\end{array}$ \\
\hline SRNL-T12 & $\begin{array}{l}5.05 \\
0.0587 \\
0.1127\end{array}$ & 0.235 & 0.940 & 0.668 & 9.9 & 65. & $\begin{array}{l}1.293 \\
65.84\end{array}$ \\
\hline
\end{tabular}

In addition, two other reports provided additional test data, allowing us to broaden our scope and test the applicability of our kinetic model. The first report, PNNL-17368, Characterization and Leach Testing for REDOX Sludge and S-Saltcake Actual Waste Sample Composites, pertained to leach tests performed on Hanford Reduction-Oxidation (REDOX) sludge material, of which four datasets were gathered. The second source was the Savannah River National Laboratory (SRNL) 
RPP-RPT-45806 Rev. 0

report SRNL-STI-2009-00180, Tank 12 Sludge Characterization and Aluminum Dissolution Demonstration, for a single leaching experiment performed over the course of 26 days. These datasets were used to evaluate the model coefficients obtained from fitting simulant data.

\subsection{MODELING RESULTS AND DISCUSSION}

The model's fit to the simulant boehmite leaching experimental data is shown in Figure 21Error! Reference source not found. . Determination of least-squares fit kinetic parameters provided values of $\mathbf{A}=5.0 \times 10^{12}$ hour $^{-1}$ and $E_{A}=90 \mathrm{~kJ} / \mathrm{mole}$. It is important to mention that, although the values of the kinetic parameters were optimized by the routine solver in Microsoft ${ }^{\circledR}$ EXCEL $^{1}$ and yielded a small root mean square error (RMSE), the sensitivity analysis of the $\mathbf{A}$ and $E_{A}$ kinetic parameters indicated that multiple sets of $\mathbf{A}$ and $E_{A}$ parameters resulted in low RMSEs. With this said, we optimized kinetic parameters by constructing a grid of varying $\mathbf{A}$ and $\mathrm{E}_{\mathrm{A}}$ values to identify optimal fit parameters along with a visual inspection of the fit results. This trial-and-error procedure proved adequate at identifying an acceptable minimum. All eight leaching experiments provided a total RMSE of 0.0326 . This fit was very accurate at near zero initial aluminate plus dissolved gibbsite, as well as for substantial initial aluminate experiments. The squared errors between simulant data and model predictions were between 5.0E-08 and 1.0E-02. The largest square error value occurred for the BCT3-5 data at $24 \mathrm{~h}$, where the modeled concentration was about $40 \%$ lower than the observed value.

Once the constant kinetic $\mathbf{A}$ and $\mathrm{E}_{\mathrm{A}}$ parameters were optimized from the fit to the simulant data, these values were subsequently used to reproduce actual waste boehmite dissolution data. The results, comparing the model prediction to the actual waste leaching data from B-101, BX-110, and S-101 samples in PNNL-12026, are provided in Figure 2-2. Three types of dissolution curves were seen in the actual waste data. The first was exemplified by the B-101 and BX-110 data, which remained virtually invariant with dissolution time. The second was shown by the S101 a data, which exhibited a gradual aluminate concentration increase with dissolution time. Finally, the S-101b data illustrated a dramatic increase in total aluminate concentration with dissolution time. Most of the datasets from PNNL-12026 were well-predicted using this model. The only exception was S-101b, where dissolution was under-predicted. We note the actual waste samples were leached for longer time periods relative to that of the simulant experiments, providing a more rigorous test of the model.

\footnotetext{
${ }^{1}$ Microsoft ${ }^{\circledR}$ EXCEL is a registered trademark of the Microsoft Corporation, Redmond, Washington.
} 
Figure 2-1. Aluminate concentration versus time for eight simulant datasets taken from PNNL18176. Four contain significant initial aluminate. Experimental conditions are provided in Table 2-2. Experimental data are symbols; fit model results are curves.

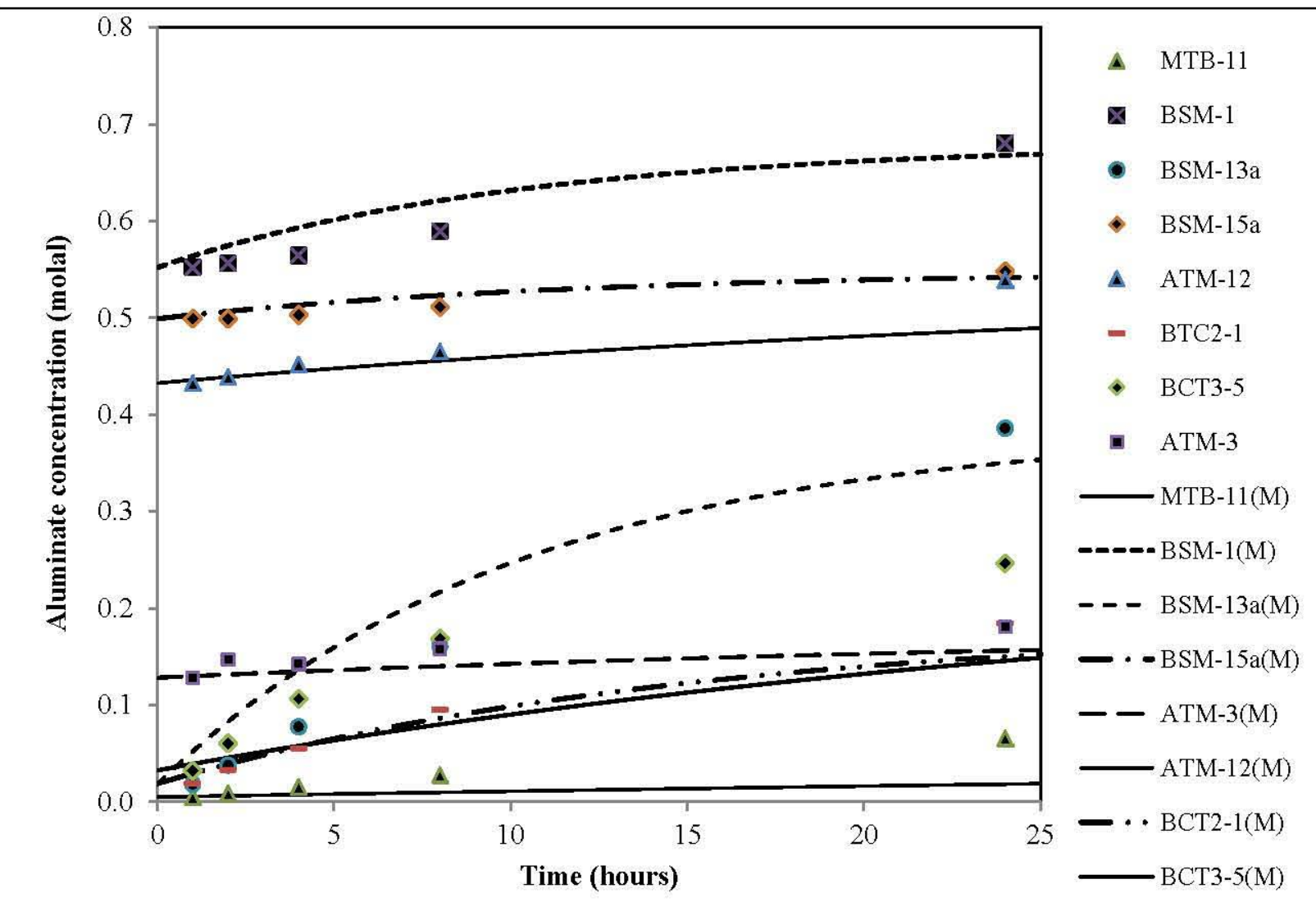


Figure 2-2. Aluminate concentration versus time for five actual waste experiments in PNNL12026. Experimental conditions are provided in Table 2-3. Experimental data are symbols; model predictions are curves.

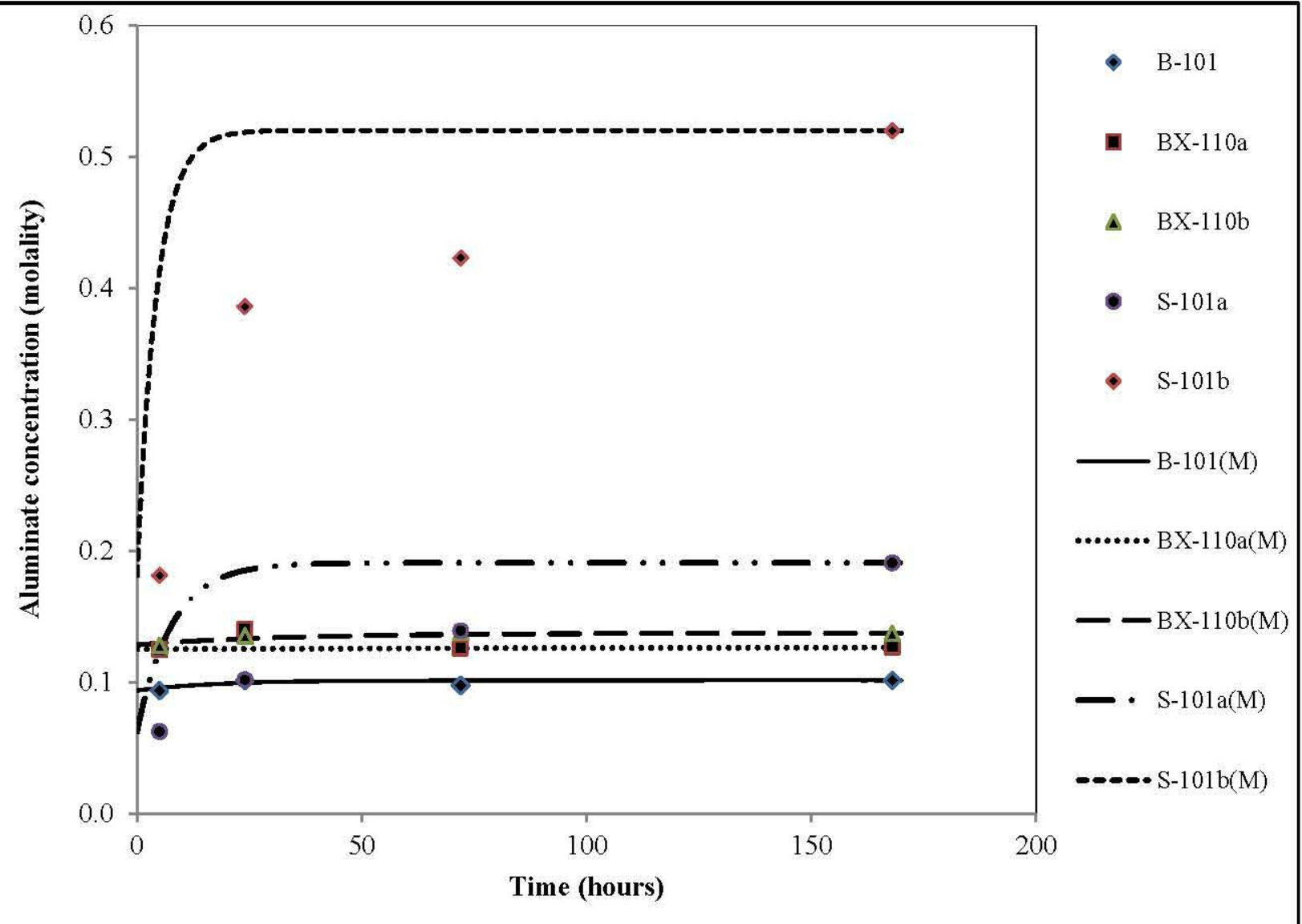

The second actual waste dataset used for comparison was the REDOX sludge boehmite leaching performed in PNNL-17368, shown in Figure 2-3. Their data provided a difficult test case for our model. The Group 5 REDOX material used for their study had become "dried monolithic chunks" during its 7-12 year laboratory storage time prior to leaching (PNNL-17368). This was confirmed by transmission electron microscopy (TEM) imaging of the solid particulate material, which indicated agglomeration/cementation of small primary boehmite particles in their samples. Imaging studies revealed that the approximately cubic crystal habit shape with an $82 \mathrm{~nm}$ edge length resulted in a specific surface area of $24 \mathrm{~m}^{2} / \mathrm{g}$. Their assumed size, applicable for individual particulates, was likely an inadequate assumption for their dataset. A measured BET specific surface area of $26 \mathrm{~m}^{2} / \mathrm{g}$ was used in our modeling effort. Comparison of our model predictions to their data indicated an over-prediction for dissolution, consistent with particleparticle agglomeration. This phenomenon would result in a slowing of the observed dissolution. 
Figure 2-3. Aluminate concentration versus time for four REDOX waste experiments described in PNNL-17368. Experimental conditions are provided in Table 2-3. Experimental data are symbols; model predictions are curves.

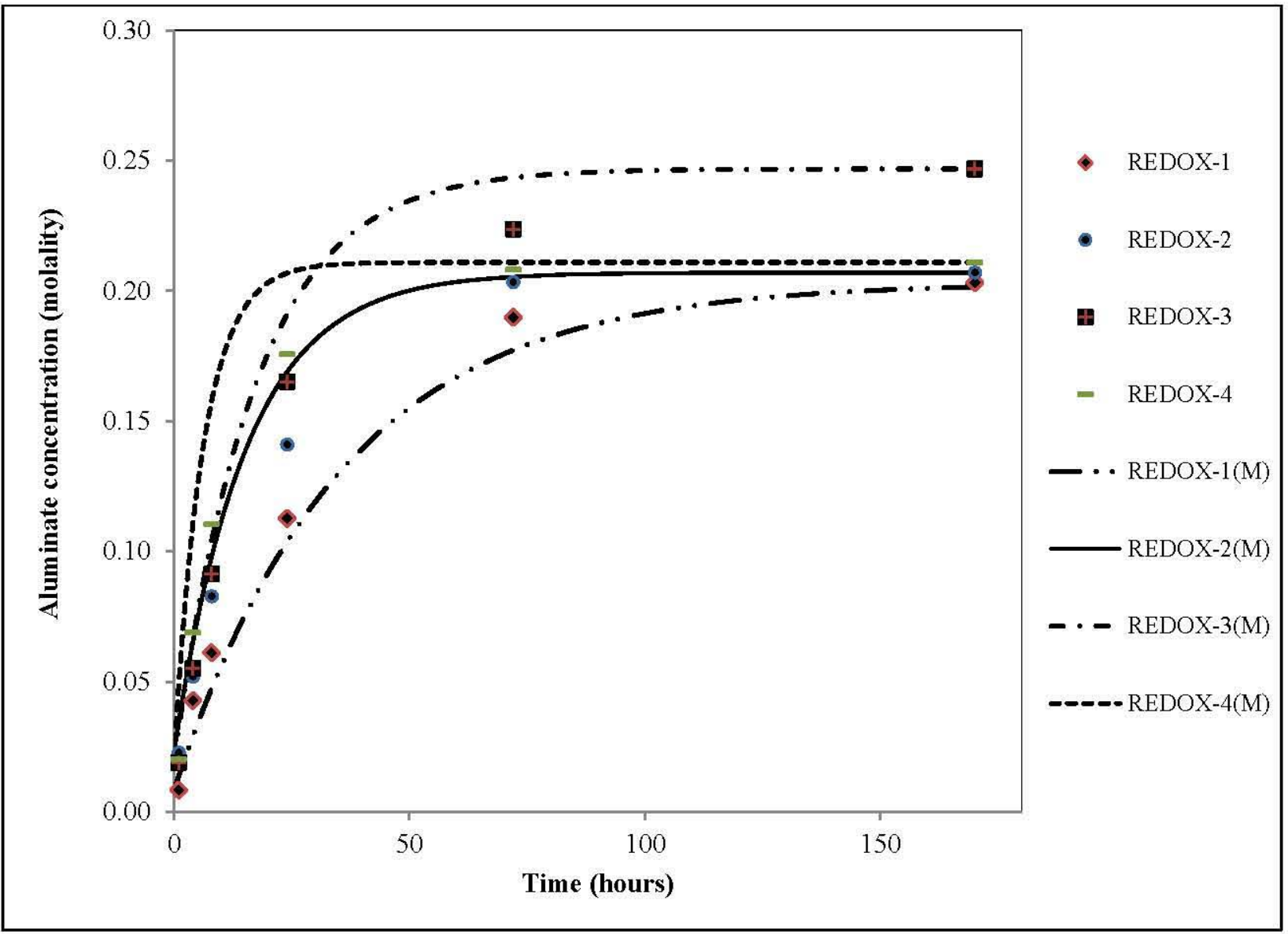

The third and final dataset analyzed was the Savannah River Tank 12 leach data detailed in SRNL-STI-2009-00180. Figure 2-4Error! Reference source not found. shows the comparison between our model's prediction and their aluminum leaching data. We see that, despite the long leach time involved, reasonable agreement was observed between the two. The difference observed between the model and data at late time is due to the model's saturation limit being reached for aluminate production from boehmite. The system contained a boehmite concentration in excess of aluminate saturation with respect to boehmite, and lead to the inability of the model to predict complete dissolution, which was observed in the experimental data set. This leads one to believe that either the documented values from the experimental data are inaccurate or that the solubility limit for boehmite is in error, perhaps due to the complex solute matrix employed in the study [see long time behavior of Figure 2-4]. It is uncertain which is the case here. 
Figure 2-4. Aluminate concentration versus time for the SRNL waste experiment detailed in SRNL-STI-2009-00180. Experimental data are symbols; model results are curves. $\mathbf{A}=5.0 \times 10^{12}$, $\mathrm{E}_{\mathrm{A}}=90 \mathrm{~kJ} / \mathrm{mole}$ for SRNL-T12(M).

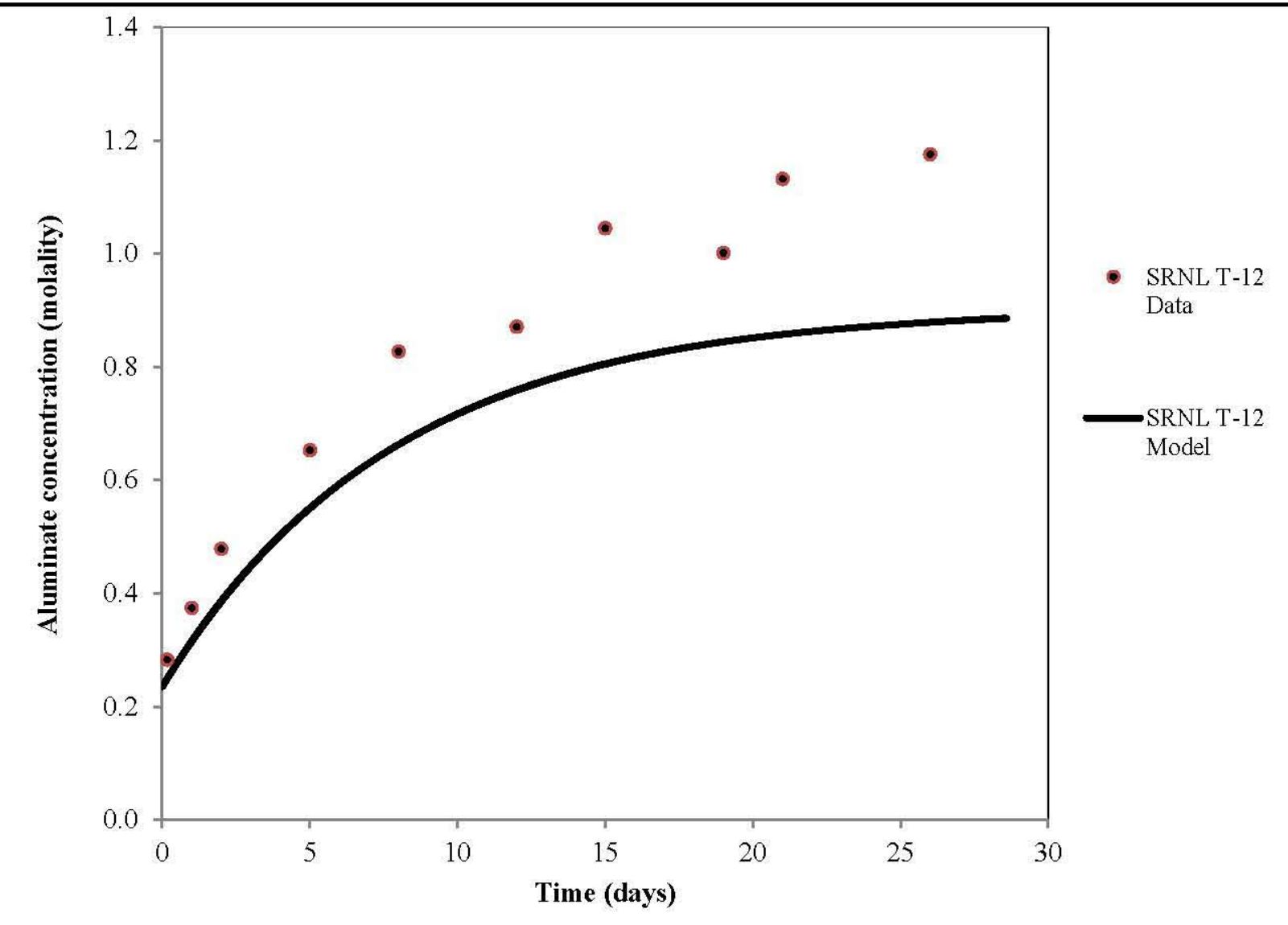

The success of Eq. (14) at predicting dissolution was proven by its ability to predict a wide range of boehmite data; all with identical Arrhenius rate coefficient parameters, $\mathbf{A}$ and $\mathrm{E}_{\mathrm{A}}$. Figure $2-2$ and Figure 2-3 indicated Eq. (14) could predict laboratory dissolution accurately using these parameters. As described by Paglia et al. 2004, the transition state for mineral dissolution using hydroxide is a poorly defined surface species produced from the de-protonation/hydroxylation of the mineral surface by $\mathrm{OH}^{-}$in solution, where the dissolution rate of these (hydr)oxide minerals is proportional to the number of these surface species. This number, according to "Temperature Dependence of Point of Zero Charge of Alumina and Magnetite" (Tewari and McLean 1972) and "The Point of Zero Charge of Pseudoboehmite" (Alwitt 1972), depends upon the hydroxide concentration, ionic strength, and temperature. Consequently, the surface charge and apparent activation energy are known to depend on $\mathrm{pH}$ and ionic strength, as indicated in "On Points of Zero Charge" (Sposito 1998) and "On the Temperature Dependence of Mineral Dissolution" (Casey and Sposito 1992). These two terms are interrelated, and may vary slightly between systems.

A more advanced boehmite dissolution kinetic model that took into account changes in surface charge with solution properties was developed by Bénézeth et al. 2008. Their model was 
applicable for much lower $\mathrm{pH}$ values and ionic strengths than analyzed here. For our application, the surface charge and apparent activation energy were approximated as constants in Eq. (14). This was due to insufficient data available to determine the surface charge more precisely under conditions relevant to nuclear waste caustic leaching. Unfortunately, it is unlikely that the surface charge can be determined under these conditions using current methods. Surface charge is typically measured during titrations, measuring the amount of protons adsorbed or desorbed from the surface as the $\mathrm{pH}$ is altered (see Sposito, 1998). Under waste leaching conditions, the amount of protons desorbed from the surface would be negligibly small compared to the total amount of hydroxide in solution (e.g., between 1 and 8 molal free hydroxide), making it difficult to accurately determine surface charge.

For our analysis we assumed $C=1$ in Eq. (14), making the surface charge a negligible function of hydroxide concentration. This was done due to the observation that a large change in hydroxide concentration (e.g. from 1 to 8 molal) only results in a relatively small change in $\mathrm{pH}(14.0<$ $\mathrm{pH}<14.9$ ). As a consequence, $\mathrm{E}_{\mathrm{A}}$ and $\mathbf{A}$ may be nearly independent of hydroxide concentration in this range. The success of this approach for most of the analyzed data sets justified this approximation when waste specific data was unavailable. For waste samples that were less successfully predicted, we believe our approximation of the constants $\mathrm{E}_{\mathrm{A}}$ and $\mathbf{A}$ for differing waste types may indicate a limitation of this assumption. Therefore, when differing waste types or greatly varying dissolution times are to be predicted using a unique set of kinetic parameters, waste-specific kinetic parameters should be employed. It is possible to refine this model in the future if estimates of boehmite surface charge under "waste-specific" conditions become available.

Predicting aluminum dissolution kinetics of greatly varying waste types can be considered risky, even if "interpolative" models, using experimental data with bounding parameters, have been fit to the datasets. Conversely, if waste-specific information is known, even if the predictions are "extrapolative" or outside the fit parameter space, agreement will likely exist between model predictions and observed leaching behavior. This is due to the robust nature and rigor of our model in its multiplicative scaling relationships addressing aluminate saturation, boehmite specific surface area, boehmite concentration, hydroxide concentration, as well as the Arrhenius $\mathbf{A}$ and $\mathrm{E}_{\mathrm{A}}$ parameters. These ideally would not be expected to depend upon waste type, as is seen in the satisfactory agreement between the SRNL and Hanford waste dissolution studies. As an example, the SRNL-T12 dataset (see Figure 2-4) had very good agreement between modeled and measured dissolution, using identical kinetic parameters.

Should situations arise where improved agreement is needed, although not seen in the datasets here, waste-specific kinetic parameters could be obtained. This approach could then be implemented in practice for boehmite leaching (such as that at Hanford) by performing laboratory characterizations of the kinetics of leaching for each waste batch to obtain their unique kinetic parameters. Additional waste-specific information, such as specific surface area from SEM imaging studies of crystal habit and size, would also improve our model's predictive capabilities. These parameter values could then be used to predict the aluminate concentration versus time profile for the full batch, and subsequently in the leaching unit operation process. Global parameters would continue to be used when waste specific data was unavailable. 


\subsection{CONCLUSIONS}

A kinetic model for boehmite leaching in caustic solutions, based on dissolution and reprecipitation, was derived using information provided by Brantley et al. 2008 and Laidler 1987. This model was then applied to both simulant and Hanford tank waste sludge samples. Simulant data was used to determine unknown Arrhenius parameters in the model. These were set as constants for predicting published Hanford tank waste sludge leaching data. Model inputs included gibbsite and boehmite initial molal concentrations, boehmite saturation molal concentration, the estimated specific surface area for boehmite, temperature, free hydroxide concentration, solution specific density, weight $\%$ water, surface charge density, and kinetic $\mathbf{A}$ and $\mathrm{E}_{\mathrm{A}}$ parameters.

Actual waste time-to-dissolution leaching data was predicted with good accuracy using simulant fit kinetic parameters. The highly alkaline conditions for the leaching data that was fit using our model indicate that, although the free hydroxide concentration varies substantially between 1 and 8 molal, the expected surface charge density remains saturated. This allowed for nearly constant values for the kinetic parameters, $\mathrm{E}_{\mathrm{A}}$ and $\mathbf{A}$. This is consistent with our model assumptions and provided successful modeling results. Improvements to the model could be obtained by fitting waste-specific leaching data to obtain a unique pair of kinetic values for each tank/batch as well as an indication of the degree of error associated with these fit constant values.

In summary, this study enhances our ability to predict schedule and cost by applying this model to aluminum dissolution in actual Hanford wastes during processing. This could be accomplished by incorporating this model into a master flowsheet for the overall waste treatment complex. This would provide an accurate estimation of the extent of boehmite dissolution versus leaching time for a globally fit set of kinetic parameters applicable to a spectrum of leaching waste types. In another application of this model, it may prove advantageous to use batchspecific derived kinetic parameters to enhance model accuracy for aluminum solids dissolution. In this approach, unforeseen contributing factors to the current model's inaccuracy could be lessened. 
RPP-RPT-45806 Rev. 0

\subsection{REFERENCES}

Addai-Mensah, J., J-A. Dawe, and J. Ralston, 2000, "The Dissolution and Interactions of Gibbsite Particles in Alkaline Media," in Proceedings of the XXI International Mineral Proceedings Congress, Vol. C, pp. 1-71, Rome, Italy.

Alwitt, R. S., 1972, "The Point of Zero Charge of Pseudoboehmite," Journal of Colloid and Interface Science, Vol. 40, pp. 195-198.

Bénézeth, P., D. A. Palmer, and D. J. Wesolowski, 2008, "Dissolution/Precipitation Kinetics of Boehmite and Gibbsite: Application of a pH-Relaxation Technique to Study NearEquilibrium Rates," Geochimica et Cosmochimica Acta, Vol. 72, Iss. 10, pp. 2429-2453.

Blesa, M. A., P. J. Morando, and A. E. Regazzoni, 1994, Chemical Dissolution of Metal Oxides, CRC Press, Inc., Boca Raton, Florida.

Brantley, S. L., J. D. Kubicki, and A. F. White, 2008, Kinetics of Water-Rock Interaction, Springer Science+Business Media, LLC, New York, New York.

Casey, W. H. and G. Sposito, 1992, "On the Temperature Dependence of Mineral Dissolution," Geochimica et Cosmochimica Acta, Vol. 56, pp. 3825-3830.

Dash, B., B. C. Tripathy, I. N. Bhattacharya, S. C. Das, C. R. Mishra, and B. S. Pani, 2007, "Effect of Temperature and Alumina/Caustic Ratio on Precipitation of Boehmite in Synthetic Sodium Aluminate Liquor," Hydrometallurgy, Vol. 88 (1-4), pp. 121-126.

Furrer, G. and W. Stumm, 1986, "The Coordination Chemistry of Weathering: I. Dissolution Kinetics of $\delta-\mathrm{Al}_{2} \mathrm{O}_{3}$ and $\mathrm{BeO}$, , Geochimica et Cosmochimica Acta, Vol. 50, Iss. 9, pp. $1847-1860$.

Gimpel, R. F. and D. A. Reynolds, 2008, "Determining Aluminum Compounds and Amounts in Hanford Tank Waste," in The $12^{\text {th }}$ International High-Level Radioactive Waste Management Conference Proceedings, Las Vegas, Nevada.

Gong, X. Y., M. X. Qian, J. Liu, L. A. Pederson, D. T. Hobbs, and N. G. McDuffie, 2003, "Gibbsite to Boehmite Transformation in Strongly Caustic and Nitrate Environments," Industrial and Engineering Chemistry Research, Vol. 42 (10), pp. 2163-2170.

Grenman, H., T. Salmi, D. Y. Murzin, and J. Addai-Mensah, 2010, "Dissolution of Boehmite in Sodium Hydroxide at Ambient Pressure: Kinetics and Modeling," Hydrometallurgy, Vol. 102 , pp. 22-30.

Johnston, C. T., S. F. Agnew, J. R. Schoonover, J. W. Kenney III, B. Page, J. Osborn, and R. Corbin, 2002, "Raman Study of Aluminum Speciation in Simulated Alkaline Nuclear Waste," Environmental Science and Technology, Vol. 36, Iss. 11, pp. 2451-2458.

Konigsberger, E., P. M. May, and G. Hefter, 2006, "Comprehensive Model of Synthetic Bayer Liquors. Part 3. Sodium Aluminate Solutions and the Solubility of Gibbsite and Boehmite,"Monatshefte Fur Chemie/Chemical Monthly, Bol 137, No. 9, pp. 1139-1149.

LBL-21482, 1988, Thermochemical Properties of Gibbsite, Bayerite, Boehmite, Diaspore, and the Aluminate Ion between 0 and $350^{\circ} \mathrm{C}$, Lawrence Berkeley National Laboratory, Berkeley, California. 
Laidler, K.J., 1987, Chemical Kinetics, $3^{\text {rd }}$ edition, Pearson Education Co., New York, New York.

Lefèvre, G., M. Duc, and M. Fédoroff, 2004, "Effect of Solubility on the Determination of the Protonable Surface Site Density of Oxyhydroxides," Journal of Colloid and Interface Science, Vol. 269, Iss. 2, pp. 274-282.

Paglia, G., C. E. Buckley, T. J. Udovic, A. L. Rohl, F. Jones, C. F. Maitland, and J. Connolly, 2004, "Boehmite-Derived g-Alumina System. 2. Consideration of Hydrogen and Surface Effects," Chemistry of Materials, Vol. 16, Iss. 10, pp. 1914-1923.

Packter, A., 1976, "Studies on Recrystallised Aluminum Mono-Hydroxide Precipitates. Kinetics of Dissolution by Sodium Hydroxide Solutions," Colloid and Polymer Science, Vol. 254, No. 11, pp. 1024-1029.

Peterson, R. A., G. J. Lumetta, B. M. Rapko, and A. P. Poloski, 2007, "Modeling of Boehmite Leaching from Actual Hanford High-Level Waste Samples," Separation Science and Technology, Vol. 42, Iss. 8, pp. 1719-1730.

Piedra, G., J. J. Fitzgerald, N. Dando, S. F. Dec, and G. E. Maciel, 1996, "Solid-State ${ }^{1}$ H NMR Studies of Aluminum Oxide Hydroxides and Hydroxides," Inorganic Chemistry, Vol. 35, Iss. 12 , pp. 3474-3478.

PNNL-12026, 1998, Washing and Caustic Leaching of Hanford Tank Sludge: Results of FY1998 Studies, Pacific Northwest National Laboratory, Richland, Washington.

PNNL-17368, 2008, Characterization and Leach Testing for REDOX Sludge and S-Saltcake Actual Waste Sample Composites, Pacific Northwest National Laboratory, Richland, Washington.

PNNL-18176, 2009, Development and Characterization of Boehmite Component Simulant, Pacific Northwest National Laboratory, Richland, Washington.

Reynolds, J. G. and R. Carter, 2008, "Reconciliation of Solute Concentration Data with Water Contents and Densities of Multi-Component Electrolyte Solutions," Journal of Solution Chemistry, Vol. 37, No. 8, pp. 1113-1125.

Snow, L. A., G. J. Lumetta, S. Fiskum, and R. A. Peterson, 2008, "Boehmite Actual Waste Dissolution Studies," Separation Science and Technology, Vol. 43, Iss. 10, pp. 29002916.

Skoufadis, C., D. Panias, and I. Paspaliaris, 2003, "Kinetics of Boehmite Precipitation from Supersaturated Sodium Aluminate Solutions," Hydrometallurgy, Vol. 68, pp. 57-68.

Spencer, B. B., J. L. Collins, and R. D. Hunt, 2005, "Effects of Sodium Hydroxide and a Chelating Agent on the Removal of Aluminum from Radioactive Sludge," Separation Science and Technology, Vol. 40, Iss. 1-3, pp. 543-569.

Sposito, G., 1998, "On Points of Zero Charge," Environmental Science and Technology, Vol. 32, pp. 2815-2819.

SRNL-STI-2009-00180, 2009, Tank 12 Sludge Characterization and Aluminum Dissolution Demonstration, Rev. 0, Savannah River National Laboratory, Aiken, South Carolina. 
SVF-1866 Rev.1, Development of a Kinetic Model of Boehmite Dissolution in Caustic Solutions Applied to Optimize Hanford Waste Processing, Washington River Protection Solutions LLC, Richland, Washington.

Tewari P. H. and A. W. McLean, 1972, "Temperature Dependence of Point of Zero Charge of Alumina and Magnetite," Journal of Colloid and Interface Science, Vol. 40, Iss. 2, pp. 267-272. 


\section{DISTRIBUTION SHEET}

\begin{tabular}{|c|c|c|c|c|c|}
\hline $\begin{array}{l}\text { To } \\
\text { J.G. Reynolds }\end{array}$ & $\begin{array}{l}\text { From } \\
\text { R.S. Diss }\end{array}$ & & & 1 of & \\
\hline Document/Project Title/ & & & & $1 / 5 / 2011$ & \\
\hline Development of a Kinet & mite Dissol & in Caustic & & Vo. NA & \\
\hline Solutions Applied to Op & Vaste Proce & & & No. NA & \\
\hline Name & MSIN & $\begin{array}{l}\text { Text With } \\
\text { All Attach. }\end{array}$ & $\begin{array}{l}\text { Text } \\
\text { Only }\end{array}$ & $\begin{array}{l}\text { Attach./ } \\
\text { Appendix } \\
\text { Only }\end{array}$ & $\begin{array}{c}\text { EDT/ECN } \\
\text { Only }\end{array}$ \\
\hline J.G. Reynolds & B1-55 & & & & \\
\hline D.L. Herting & T6-07 & & & & \\
\hline T.W. Crawford & $\mathrm{B} 1-55$ & & & & \\
\hline D. Shuford & B1-55 & & & & \\
\hline K.G. Carothers & R2-58 & & & & \\
\hline D.E. Place & B1-55 & & & & \\
\hline S.J. Harrington & $\mathrm{B} 1-55$ & & & & \\
\hline J.H. Rasmussen & B1-55 & & & & \\
\hline D.M. Nguyen & $\mathrm{B} 1-55$ & & & & \\
\hline D. Banning & $\mathrm{B} 1-55$ & & & & \\
\hline D.A. Greer & B1-55 & & & & \\
\hline R.B. Mabrouki & T6-07 & & & & \\
\hline J.N. Appel & B1-55 & & & & \\
\hline K.R. Seniow & B1-55 & & & & \\
\hline E.B. West & B1-55 & & & & \\
\hline R. S. Disselkamp & B1-55 & & & & \\
\hline & & & & & \\
\hline & & & & & \\
\hline & & & & & \\
\hline & & & & & \\
\hline & & & & & \\
\hline & & & & & \\
\hline & & & & & \\
\hline & & & & & \\
\hline & & & & & \\
\hline & & & & & \\
\hline & & & & & \\
\hline & & & & & \\
\hline & & & & & \\
\hline & & & & & \\
\hline
\end{tabular}

